
JPC 92-3144

\title{
Krypton Ion Thruster Performance
}

\author{
Michacl J. Patterson* \\ National Aeronautics and Space Administration \\ Lewis Research Center \\ George J. Williams, $\mathbf{J r}^{+}$ \\ Department of Aerospace Engineering \\ Aubum University
}

\begin{abstract}
Preliminary data were obtained from a $30 \mathrm{~cm}$ ion thruster operating on krypton propellant over the input power range of 0.4-5.5 $\mathrm{kW}$. The data are presented, and compared and contrasted to those obtained with xenon propellant over the same input power envelope. Typical krypton thruster efficiency was 70 percent at a specific impulse of approximately $5000 \mathrm{~s}$, with a maximum demonstrated thrust-to-power ratio of approximately 42 $\mathrm{mN} / \mathrm{kW}$ at $2090 \mathrm{~s}$ specific impulse and 1580 watts input power. Critical thruster performance and component lifetime issues were evaluated. Order-of-magnitude power throttling was demonstrated using a simplified power-throttling strategy.
\end{abstract}

\section{Introduction}

Recent studies have examined the potential use of krypton ion thruster-propelled electric orbit transfer vehicles for near-Earth space mission applications. ${ }^{1,2}$ For these mission studies, krypton was selected over xenon as the propellant because of concern over the cost and availability of the quantities of xenon required for high energy space missions. ${ }^{3}$ Other analyses indicate, however, that the xenon production capacity is probably more than adequate for nearer-term electric propulsion applications. ${ }^{4}$

Regardless of issues driving the selection of the thruster propellant, only limited data exist for krypton ion thruster performance. ${ }^{5,6}$ The krypton thruster mission studies conducted to date have used projections of thruster performance obtained from data on other propellants for mission assessments. Hence it is of interest to establish a performance database on krypton propellant.

To this end, a performance assessment of a $30 \mathrm{~cm}$ diameter, derated ion thruster, ${ }^{7-9}$ originally developed and optimized for xenon propellant, was conducted with krypton propellant. This effort has emphasized a comparative assessment of overall thruster performance and lifetime expectations to that obtained with xenon propellant.

\section{Apparatus and Procedure}

A $30 \mathrm{~cm}$ diameter laboratory-model ion thruster was used to conduct the performance tests. The thruster, originally developed and optimized for xenon, ${ }^{7}$ incorporated a segmented-anode geometry consisting of 3 stainless steel segments and has an exterior chamber of $0.76 \mathrm{~mm}$ thick cold rolled steel. The thruster uses a 'reverse-injection' propellant system for the main flow to reduce the neutral loss rate associated with the use of krypton propellant. A low-mass magnetic circuit design was employed using samarium-cobalt permanent magnets arranged to form a ring-cusp field boundary., ${ }^{6,8}$ Conventional hollow cathodes, consisting of a molybdenumrhenium alloy tube and a thoriated tungsten orifice plate were employed in the discharge chamber and in the neutralizer. The orifice diameters of the discharge and the neutralizer cathodes were $1.52 \mathrm{~mm}$ and $0.51 \mathrm{~mm}$, respectively. The cathodes utilize porous tungsten inserts impregnated with a low work function compound as the

\footnotetext{
Copyright 1992 by the American Institute of Aeronautics and Astronautics, Inc. No copyright is asserted in the United States under Title 17, U.S. Code. The U.S. Government has a royalty-free license to exercise all rights under the copyright claimed herein for Government purposes. All other rights are reserved by the copyright owner.

*Aerospace Engineer, member AIAA

${ }^{\dagger}$ Graduate Student, student member ALAA
} 


\section{KR YPTON ION THRUSTER PERFORMANCE}

electron emitters.

Testing was conducted with 2 separate sets of twogrid ion optics. The ion optics specifications for these sets are shown in Table I. Grid set 1 had previously been found to give high perveance performance with xenon propellant. ${ }^{7}$ The change to the grid set 2 was driven by the need to increase propellant efficiency and hence overall thruster efficiency by reducing the ion optics neutral transparency.

Laboratory power supplies ${ }^{10}$ were used for thruster performance testing with a total of 7 power leads running to the thruster. The thruster uses 4 power circuits for steady-state operation, and has 2 additional heater circuits for start-up of the discharge and neutralizer cathodes. The thruster does not incorporate a discharge cathode keeper or starting electrode. Discharge cathode and neutralizer cathode ignition are obtained using the open circuit voltages of the discharge and neutralizer keeper power supplies, respectively.

The propellant feedsystem is of an all-electropolished stainless-steel tubing construction, with welds and metalgasket seals to minimize out-gassing and leaks. The three feed lines to the thruster (main, cathode, and neutralizer) incorporated individual commercial mass flow transducers to measure the propellant flow rate. Each transducer was calibrated using a primary standard.

Thruster performance testing was conducted in the Tank 5 vacuum chamber facility at the NASA Lewis Research Center (LeRC). The vacuum chamber dimensions are $4.6 \mathrm{~m}$ diameter by $19.2 \mathrm{~m}$ length. The pumping speed of the facility is a nominal $110 \mathrm{k} \ell / \mathrm{s}$ for krypton, giving a no-load pressure of $\leq 6.7 \times 10^{-5} \mathrm{~Pa}$, and an operational pressure of $\leq 8.9 \times 10^{-3} \mathrm{~Pa}$.

Procedures used to obtain thruster performance are comparable to those described in Reference 7. These include (1) identifying and establishing the appropriate discharge chamber and neutralizer operating conditions; and (2) adjusting the ion optics voltages over the broadest possible range of net-to-total voltage for several values of beam current and total voltage.

The thruster was operated under manual control for all performance testing. Test data were recorded from calibrated metering, and calculated performance data were corrected for thrust losses associated with beam divergence and doubly-charged ions. Total efficiency and specific impulse calculations included losses associated with accelerator drain and neutralizer power, and neutralizer flow rate. All propellant efficiencies included a correction to the mass flow rate for propellant ingested from the facility. A detailed discussion of the thruster performance and lifetime calculations used in this investigation may be found in Reference 7 .

\section{Thruster Performance}

The thruster performance characteristics presented in this section include discharge chamber performance, ion optics performance, and characterization of overall thruster efficiency as a function of specific impulse. Additionally, a simplified power-throttling strategy, identified and demonstrated in the testing, is presented. Comparable performance data presented using xenon propellant are from Reference 7.

\section{Discharge Chamber Performance -}

As anticipated, the immediate impact of switching from xenon to krypton as the propellant was manifested in discharge and neutralizer cathode ignition. Discharge ignition with xenon was routinely obtained at total discharge chamber flow rates of approximately $20 \mathrm{sccm}$, with application of $\leq 75 \mathrm{~V}$ anode voltage. ${ }^{7}$ With operation on krypton, the minimum total discharge chamber flow rate to initiate a discharge was approximately 80 sccm of propellant. Additionally, to obtain reliable ignition, an open circuit anode voltage of $\sim 150 \mathrm{~V}$ was required and used. The neutralizer cathode typically required $100 \mathrm{~V}$ on the keeper electrode to ignite, approximately a factor of 7 higher voltage than that required with xenon, at a flow rate of approximately $10 \mathrm{sccm}$.

Figure 1 compares the discharge losses as a function of beam current found for xenon and krypton for data obtained at $\geq 80 \%$ discharge chamber propellant efficiency with grid set 1. As indicated in Figure 1, the discharge losses operating on krypton propellant were approximately 50 to 75 watts per beam ampere higher than those obtained with xenon, for beam currents less than $2 \mathrm{~A}$. Above approximately $2 \mathrm{~A}$, the difference in the discharge losses between the two propellants decreases. The difference in discharge losses was due to the difference in required discharge voltages. All data with xenon were obtained at $28 \mathrm{~V}$. The krypton data were obtained at 40,36 , and 32 volts, with the required voltage decreasing with beam current.

To obtain useful propellant efficiencies, consistent with high overall krypton thruster performance, necessitated operation at high $(\geq 32 \mathrm{~V})$ discharge chamber voltages. To improve the propellant and overall thruster efficiencies and permit operation at lower discharge chamber voltages, the ion optics were changed from set 1 to set 2, which had a lower accelerator grid physical open area. Discharge chamber performance data, at conditions of constant beam current and discharge voltage, were then obtained with the thruster using grid set 2. Changing to grid set 2 increased the discharge chamber propellant efficiency by as much as $9 \%$ for a 


\section{KRYPTON ION THRUSTER PERFORMANCE}

given discharge voltage. Good correlation was indicated between the measured neutral loss rates and the ion optics neutral transparencies as calculated from the modified physical open area fraction of the accelerator grids. All further performance assessments were subsequently conducted with grid set 2 , as these optics provided approximately a factor of 1.7 decrease in neutral loss rate.

Figures 2 and 3 show the discharge chamber performance of the thruster with grid set 2. In Figure 2, the discharge losses are plotted versus the discharge chamber propellant efficiency for various values of beam current at a constant discharge voltage of $32 \mathrm{~V}$. As indicated, the discharge chamber propellant efficiencies exceeded $90 \%$ at a beam current of $3.2 \mathrm{~A}$. Figure 3 shows similar discharge performance curves, but for various values of discharge voltage at a constant beam current of $1.45 \mathrm{~A}$. As expected, the maximum obtainable propellant efficiencies increased as the discharge voltage was increased.

\section{Ion Optics Performance -}

Improving/optimizing discharge chamber performance was a prime consideration in selecting the ion optics geometry. Hence, grid set 2 was used for the bulk of the krypton thruster performance evaluation. Obtaining and demonstrating maximum thrust-to-power with krypton propellant was not a primary consideration because other issues, including lifetime, were deemed more relevant in the near-term development of a krypton thruster. Thus the thruster performance data were taken well within the perveance boundary obtainable with the ion optics. It is of value to note, however, the typical perveance obtained with krypton and how the data compare to that obtained with xenon.

Figure 4 shows the beam current as a function of total accelerating voltage for grid set 1 , for both xenon and krypton propellants. The data of Figure 4 show no discernable increase in limiting perveance on switching to the lighter weight propellant krypton, although the ChildLangmuir equation predicts that the current extraction capability should increase by approximately $25 \%$ with krypton propellant. These data were repeatable, and similar results were obtained in the same timeframe, on the same test stand with other thruster hardware as reported in Reference 11. It is hypothesized that this phenomenon is a consequence of elevated local beam potentials with krypton resulting in a more rapid onset of an impingement-limited perveance condition," however additional tests are required.

\section{Overall Thruster Efficiency -}

The overall thruster efficiency obtained with grid set 1 is plotted versus specific impulse in Figure 5 for both xenon and krypton propellants. The xenon data (from
Reference 7) represent peak efficiencies demonstrated with $30 \mathrm{~cm}$ xenon ion technology. The efficiency and specific impulse values with krypton range from approximately $12 \%$ efficiency at $1020 \mathrm{~s}$, to $53 \%$ efficiency at $3250 \mathrm{~s}$. No increase in specific impulse is seen with krypton as compared to xenon, which is unexpected from calculations based solely on the ratio of the square-root of the propellant atomic masses. This is because an increase in neutral losses, both from the discharge chamber and neutralizer, is experienced with krypton that negates the specific impulse increase associated with the lighter mass propellant. The data of Figure 5 with xenon and krypton were obtained over essentially the same input power range, beam currents, and ion beam and total voltages.

Further increases in specific impulse, beyond those indicated for krypton in Figure 5, were not readily obtainable with grid set 1 . This was because the optics were set at a close electrode gap which, for higher beam voltages, resulted in unacceptable arcing.

At the highest specific impulse for krypton in Figure 5 , the overall thruster efficiency is approximately 20 percentage points lower than that obtainable with xenon propellant. This reduction in efficiency with the lighter mass propellant is the result of the combined effects of higher discharge and neutralizer power and propellant losses. The krypton performance data of Figure 5 are replotted in Figure 6 on expanded scales, with the corresponding ion beam currents indicated. The two diverging bands of data points seen in Figures 5 and 6 for krypton are a consequence of the sensitivity of the discharge losses to beam current at low values of the latter. In this range, for a constant specific impulse, as the beam current is increased the discharge losses decrease resulting in higher overall thruster efficiencies. Note that the maximum indicated specific impulse at 0.8 A beam current was substantially lower than that of other beam currents, and is an artifact of the total voltage selected.

Figure 7 shows the overall thruster efficiency obtained with grid set 2 on krypton propellant, as a function of specific impulse. With these ion optics, the thruster efficiency varied from approximately $20 \%$ to $71 \%$ over a corresponding range in specific impulse from approximately $1580 \mathrm{~s}$ to $5130 \mathrm{~s}$. The increase in maximum obtainable specific impulse, from that demonstrated with grid set 1 , was approximately $1900 \mathrm{~s}$. Of this increase, approximately $500 \mathrm{~s}$ was due to reduced neutral losses associated with the lower ion optics neutral transparency, with the remaining $1400 \mathrm{~s}$ due to higher permissible beam voltages with these optics. The variation in input power for the data of Figure 7 was from approximately $430 \mathrm{~W}$ at $1580 \mathrm{~s}$ to $5510 \mathrm{~W}$ at $5130 \mathrm{~s}$. At the highest 


\section{KRYPTON ION THRUSTER PERFORMANCE}

specific impuise and thruster efficiency, the total propellant utilization efficiency, corrected for multiply-charged ions and neutralizer flow, was approximately $87 \%$ at a beam current of $3.2 \mathrm{~A}$ and $32 \mathrm{~V}$ discharge voltage. The maximum demonstrated thrust-to-power ratio was approximately $42 \mathrm{mN} / \mathrm{kW}$ at $2090 \mathrm{~s}$ specific impulse, and 1580 watts input power.

Figure 8 compares the maximum achieved thruster efficiency data for xenon and krypton versus specific impulse. The data for krypton were obtained with the low neutral transparency grid set 2 , and the xenon data were obtained with the high perveance design grid set 1 .

\section{Simplined Power-Throttling -}

Power throttling is necessary in many mission scenarios because of the corresponding changes in the solar power available for propulsion as the spacecraft's distance from the sun varies. There are several approaches to power-throttling ion thrusters, which vary in degree of effectiveness, and in power-processing and propellant flow-control requirements.

The laboratory thruster employed in present work has demonstrated a 55:1 power-throttling range capability with xenon propellant. This was accomplished by continuous adjustment of the propellant flow rates to the main plenum and to the discharge and neutralizer cathodes in conjunction with changing the discharge and beam currents, and the ion optics total voltage. This approach, referred to here as full-throttling, permits simultaneous control of all thruster parameters to maximize performance, and lifetime expectations, and power-throttling envelope. While this approach does permit a large input power-throttling range, it requires the use of active propellant flow controllers.

A second power-throttling approach is to vary the beam voltage at a fixed beam current, and maintain fixed propellant flow rates to the main plenum and discharge and neutralizer cathodes ${ }^{12}$ (referred to here as mimimum-throttling). This approach may mitigate propellant flow control requirements by using a regulated propellant feed and integral flow restrictors, eliminating the need for active control. ${ }^{12}$ However throttling at constant beam current, while theoretically permitting a factor of 3.8 in input power, ${ }^{12}$ is accomplished by large variations in net to total voltages potentially resulting in penalties in grid lifetime, and propellant efficiency. ${ }^{12}$

A third alternative to the two previous strategies is to power-throttle by varying both the beam voltage and beam current, but do so without an active flow controller. This could be accomplished by regulating the propellant feed, and incrementally varying the main plenum propel- lant flow rate (via multiple parallel feed lines with independent valving and flow restictors, or via a single feed line with a multi-position valve and flow restrictors) while maintaining fixed discharge and neutralizer cathode flow rates. This approach, referred to here as simplifiedthrottling, allows for a degree of simplification to the propellant management system as compared to full-throttling, while potentially permitting a larger power throttling range than mimimum-throttling. Additionally this approach does not require large variations in net-to-total voltage ratio, potentially mitigating grid lifetime issues. These three approaches were examined.

Figure 9 shows the maximum demonstrated powerthrottling range obtained with krypton propellant for the three throttling strategies. The available power-throttling ranges for the full-, minimum-, and simplified-throttling strategies were approximately $13,2.0$, and 12 respectively. The data for Figure 9 were generated in the following manner. The performance and operating conditions identified in Table II were established, using the fullthrottling approach, as baseline values. That is, throttling over the power range shown included variation of the main plenum propellant flow rate, as well as the discharge and neutralizer cathode flow rates. At each indicated beam current, the minimum-throttling approach was implemented in the manner proposed in Reference 12. This was accomplished by varying the net-to-total voltage ratio over the broadest available range, at fixed propellant flow rates and total accelerating voltages, and determining the maximum corresponding range in input power. The results of this strategy are shown in Figure 10 , a plot of power-throttling range versus beam current. The simplified-throttling approach was accomplished by duplicating as nearly as possible the full-throttling performance conditions of Table II, in terms of beam and total voltages and beam current, while maintaining constant discharge and neutralizer cathode flow rates. Throttling was thus accomplished through variation only of the ion optics voltages, the main plenum propellant flow rate, and the discharge current, all in discrete increments.

As indicated in Figure 9, the power-throttling ranges for the full- and simplified-throttling strategies are substantially higher, by a factor of 6 , than that obtainable with the minimum-throttling approach. This is because the full- and simplified-throttling strategies vary both the beam voltage and beam current, whereas the minimumthrottling approach varies the beam voltage at fixed beam current. As a result, the maximum power-throttling range available using the minimum-throttling approach is only approximately a factor of 2 , and this value is essentially independent of beam current as indicated in Figure 10. This range of input power is limited by the available range in net-to-total voltage ratios, which for the conditions identified in Figure 10 were from approximately 0.2 - 


\section{KRYPTON ION THRUSTER PERFORMANCE}

to-0.8. The lower limit was restricted by defocussing and direct impingement of ion beamlets onto the accelerator grid surface. The upper limit was restricted by electron backstreaming from the neutralizer.

Although the full-throttling strategy provides slightly higher power-throttling capability than that of the simplified-throttling strategy, the simplified approach does not require an active flow controller. Hence, from a powerthrottling and propellant management perspective, the simplified-throttling strategy would appear most attractive.

Figure 11 compares the thruster efficiency versus specific impulse obtained using the three throttling approaches. As indicated the thruster efficiency values for the full- and simplified-throttling strategies compare favorably. The minimum-throttling strategy efficiency values are somewhat greater than those obtained using the other 2 strategies at low values of specific impulse. This is because, for a given specific impulse, the minimum-throttling approach is processing a higher beam current, which results in lower discharge losses and higher propellant efficiencies. Note, however, this is at the expense of the available specific impulse envelope. The range of available specific impulse values using the minimum-throttling strategy is approximately 1.8 , or nearly a factor of 2 lower than that obtainable with the other throttling approaches. This result is to-first-order independent of beam current. The minimum-throttling data shown in Figure 11 were obtained at a nominal beam current of $2.8 \mathrm{~A}$. Figure 12, a plot of thruster efficiency versus input power for the three throttling approaches, indicates the magnitude of the input power levels. The power envelopes available using the full- and simplified-throttling strategies are similar, and encompass that available with the minimum-throttling approach. Additionally, at fixed input power, the thruster efficiency is higher using the full- and simplified-throttling as compared to that obtained with minimum-throttling approach, for most values of input power. This is because the minimum-throttling approach power throttles by adjusting downward the net-to-total voltage ratio which results in increased thrust-losses due to off-axis vectoring of the ion beam. The other two approaches maintain a high net-to-total voltage during power-throttling and hence do not experience significant thrust-losses.

Estimated accelerator grid lifetimes versus input power are shown in Figure $\mathbf{1 3}$ for all three throttling strategies. The lifetimes for the full- and simplifiedthrottling data are comparable, and indicate different behavior with input power than the minimum-throttling approach. This is because, as the input power is increased, the ion beam current densities and accelerator grid voltages increase, using the full- and simplified- throttling. This results in increased erosion of the accelerator grid due to charge-exchange ion impingement. However, increasing the input power level using the minimum-throttling approach results in higher beam voltages at a fixed ion beam current density. For fixed total voltages this results in a decrease in accelerator grid voltage, and hence a decrease in sputter erosion from charge-exchange ion impingement. To increase the input power level beyond that indicated in Figure 13 for the minimum-throttling curve would necessarily require an increase in total voltage, and hence an increase in accelerator grid voltage. The minimum-throttling curve would then change derivative and closely track the other two throttling curves at higher input power levels.

Estimated lifetimes for thruster internal components, such as the screen grid, cannot be used as discriminators between the full- and minimum-throttling strategies. This is because both approaches operate at equivalent discharge voltages and current densities. Operation using the simplified-throttling strategy did result in as much as a factor of two reduction in anticipated screen grid lifetimes, as compared to the other approaches. This was due to higher discharge voltages experienced as a result of operation of the discharge cathode at a constant flow rate. This decrease was however a result of the rather arbitrary flow rate established through the discharge cathode. Hence from power-throttling, propellant management, and thruster performance and lifetime considerations, operation using a simplified-throttling strategy of fixed discharge and neutralizer cathode propellant flow rates may be advantageous.

\section{Thruster Lifetime Expectations}

As is the case with xenon propellant, erosion of the accelerator grid of $30 \mathrm{~cm}$ ion thrusters due to krypton charge-exchange ion impingement and sputtering may be a major life-limiting issue. The resonance charge-exchange cross-sections and sputter yields are similar for xenon and krypton over the same energy ranges. Additionally, with krypton the higher neutral loss rates observed result in potentially higher charge-exchange ion production rates.

Unlike xenon, however, operation with krypton propellant also introduces potentially major life-limiting issues associated with internal erosion of cathode potential surfaces in the discharge chamber due to ion sputtering. This is as a consequence of the substantially higher operating discharge voltages required with krypton, and the extreme sensitivity of the sputter yields to incident ion energy. Figure 14 illustrates this point, showing estimated screen grid lifetimes versus beam current for krypton, normalized to the values obtained with xenon. As seen in the figure, the expected screen grid lifetimes operating with krypton propellant are as much as an 
order-of-magnitude lower than that anticipated for xenon at low beam current (approximately $1 \mathrm{~A}$ ), but rapidly converge with increasing beam current. The lifetimes converge at high currents since the required krypton discharge voltage decreases and approaches that of xenon. The estimates of Figure 14 were obtained assuming identical ion optics geometries and taking discharge voltages consistent with those measured during this investigation. A simple analysis was employed to estimate the low energy sputter yields for both krypton and xenon. ${ }^{7,9}$

\section{Concluding Remarks}

Preliminary data characterizing the performance and lifetime of an ion thruster were obtained with krypton propellant and compared to corresponding data obtained with xenon propellant. Testing was conducted with a 30 $\mathrm{cm}$ diameter derated ion thruster, originally developed and optimized for xenon propellant. The data characterized discharge chamber and ion optics performance, as well as overall thruster efficiency as a function of specific impulse. Additionally, a simplified power-throttling strategy was identified and demonstrated.

The demonstrated specific impulse values measured with krypton ranged from approximately $1580 \mathrm{~s}$ to $\mathbf{5 1 3 0}$ $\mathrm{s}$, over corresponding ranges in thruster efficiency from approximately $20 \%$ to $71 \%$ and input power levels from approximately $430 \mathrm{~W}$ to $5510 \mathrm{~W}$.

An investigation was undertaken which demonstrated that order-of-magnitude power throttling can be achieved with constant propellant flow rates to both discharge and neutralizer cathodes, with variation only of the main plenum propellant flow rate to the thruster discharge. This throttling scheme potentially reduces propellant management complexity by eliminating the need for an active flow controller for missions where large powerthrottling is required.

As is the case with operation on xenon propellant, erosion of the accelerator grid of $30 \mathrm{~cm}$ ion thrusters due to krypton charge-exchange ion impingement and sputtering may be a major life-limiting issue. Unlike xenon, however, operation with krypton propellant also introduces potentially major life-limiting issues associated with internal erosion of cathode potential surfaces in the discharge chamber due to ion sputtering because of the need to operate at higher discharge voltages. In particular, the lifetime of the screen grid, operating with krypton propellant, is as much as an order-of-magnitude lower than that anticipated with xenon for low beam currents (approximately 1 A). However the expected krypton and xenon screen grid lifetimes rapidly converge with increasing beam current.

\section{References}

'Miller, T.M., "Systems Analysis for an Operational EOTV," ALAA Paper No. 91-2351, June 1991.

${ }^{2}$ Miller, T.M., "Systems Analysis for an Operational EOTV," IEPC Paper No. 91-133, October 1991.

${ }^{3}$ Welle, R.P., "Availability Considerations in the Selection of Inert Propellants for Ion Engines," AIAA Paper No. 90-2589, July 1990.

${ }^{4}$ Personal communication, Sarver-Verhey, T.R., NASA-Lewis Research Center, May 1992.

${ }^{5}$ Rawlin, V.K., "Operation of the J-Series Thruster Using Inert Gas," NASA TM-82977, November 1982.

${ }^{6}$ Sovey, J.S., "Improved Ion Containment Using a Ring-Cusp Ion Thruster," NASA TM-82990, November 1982.

${ }^{7}$ Patterson, M.J., "Low-Isp Derated Ion Thruster Operation," AIAA Paper No. 92-3203, July 1992.

${ }^{8}$ Patterson, M.J., and Rawlin, V.K., "Derated Ion Thruster Design Issues," IEPC Paper No. 91-150, October 1991.

${ }^{9}$ Patterson, M.J., and Foster, J.E., "Performance and Optimization of a 'Derated' Ion Thruster for Auxiliary Propulsion," ALAA Paper No. 91-2350, June 1991.

${ }^{10}$ Patterson, M.J., and Verhey, T.R., "5kW Xenon Ion Thruster Lifetest," AIAA Paper No. 90-2543, July 1990.

"Rawlin, V.K., "Characterization of Ion Accelerating Systems on NASA's Ion Thrusters," AIAA Paper No. 923827, July 1992 .

${ }^{12}$ Garner, C.E., Brophy, J.R., and Pless, L.C., "Ion Propulsion System Design and Throttling Strategies for Planetary Missions," AIAA Paper No. 88-2910, July 1988. 
Table I Ion optics specifications.*

\begin{tabular}{c|c|c|c|c|c|c|c|c|c}
\hline $\begin{array}{c}\text { Grid } \\
\text { Set }\end{array}$ & \multicolumn{2}{|c|}{$\begin{array}{c}\text { Aperture } \\
\text { Diameter, mm }\end{array}$} & \multicolumn{2}{|c|}{$\begin{array}{c}\text { Grid } \\
\text { Thickness, mm }\end{array}$} & \multicolumn{2}{c|}{$\begin{array}{c}\text { Open Area } \\
\text { Fraction }\end{array}$} & $\begin{array}{c}\text { Cold Gap } \\
\text { Spacing, } \\
\mathrm{mm}\end{array}$ & $\begin{array}{c}\text { Neutral } \\
\text { Transparency }\end{array}$ & $\begin{array}{c}\text { Aperture } \\
\text { Shape }\end{array}$ \\
\cline { 2 - 12 } & screen & accel. & screen & accel. & screen & accel. & & & \\
\hline \hline 1 & 1.91 & 1.52 & 0.38 & 0.38 & 0.67 & 0.43 & 0.48 & 0.35 & circular \\
\hline 2 & $1.52^{* *}$ & $0.91^{*}$ & 0.25 & 0.25 & 0.74 & 0.26 & 0.66 & 0.21 & hexagonal \\
\hline \hline
\end{tabular}

*molybdenum electrode material

as measured across flats

Table II Thruster performance with krypton propellant; grid set 2.

\begin{tabular}{|c|c|c|c|c|c|c|}
\hline $\begin{array}{l}\text { Input Power } \\
P_{\text {inpl, }} \\
\quad W\end{array}$ & $\begin{array}{c}\text { Discharge } \\
\text { Voltage } V_{d} \\
V\end{array}$ & $\begin{array}{c}\text { Beam } \\
\text { Current } J_{b}, \\
\text { A }\end{array}$ & $\begin{array}{l}\text { Thrust } F \text {, } \\
\text { mN }\end{array}$ & $\begin{array}{c}\text { Thrust-to-Power } \\
\text { Ratio } \mathbf{F} / \mathbf{P}_{\text {inpos }} \\
\mathrm{mN} / \mathrm{kW}\end{array}$ & $\begin{array}{c}\text { Specific } \\
\text { Impulse } \\
\mathbf{I}_{\mathrm{sp}}, \mathbf{s}\end{array}$ & $\begin{array}{c}\text { Total Thruster } \\
\text { Efficiency } \eta_{\mathrm{t}}\end{array}$ \\
\hline 430 & 39.9 & 0.80 & 12 & 27.9 & 1580 & 0.20 \\
\hline 750 & 40.0 & 0.80 & 24 & 32.0 & 3080 & 0.47 \\
\hline 1190 & 39.8 & 1.20 & 40 & 33.5 & 3310 & 0.55 \\
\hline 1770 & 35.9 & 1.45 & 55 & 31.1 & 3750 & 0.57 \\
\hline 1960 & 35.9 & 2.00 & 67 & 34.2 & 3370 & 0.56 \\
\hline 2990 & 32.1 & 2.80 & 103 & 34.4 & 3740 & 0.63 \\
\hline 3540 & 28.0 & 3.20 & 122 & 34.5 & 3760 & 0.63 \\
\hline 4800 & 32.0 & 3.20 & 144 & 30.0 & 4720 & 0.69 \\
\hline 5510 & 32.0 & 3.20 & 157 & 28.5 & 5130 & 0.71 \\
\hline
\end{tabular}




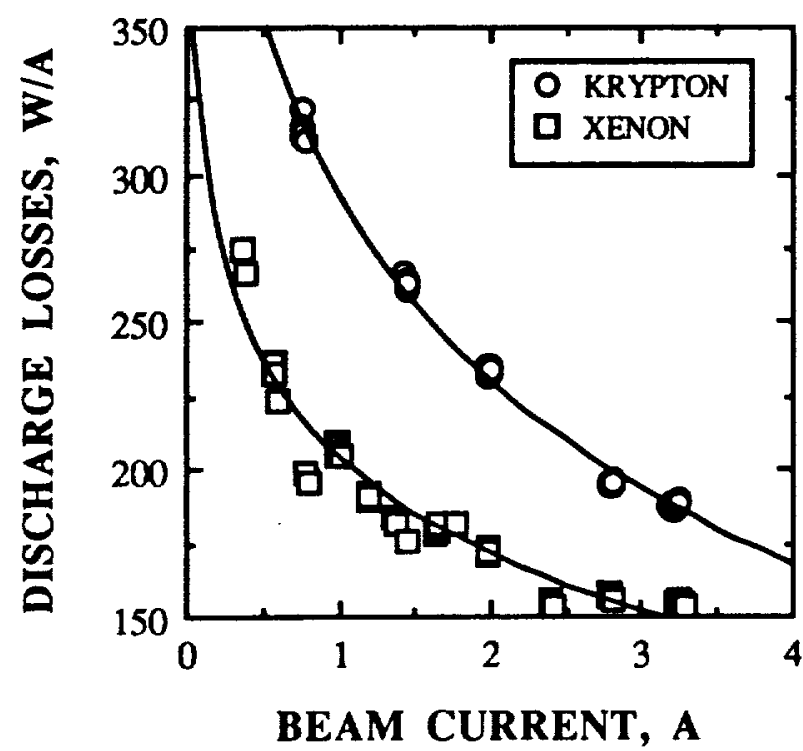

Fig. 1 Discharge losses versus beam current for xenon and krypton propellants; grid set 1 .

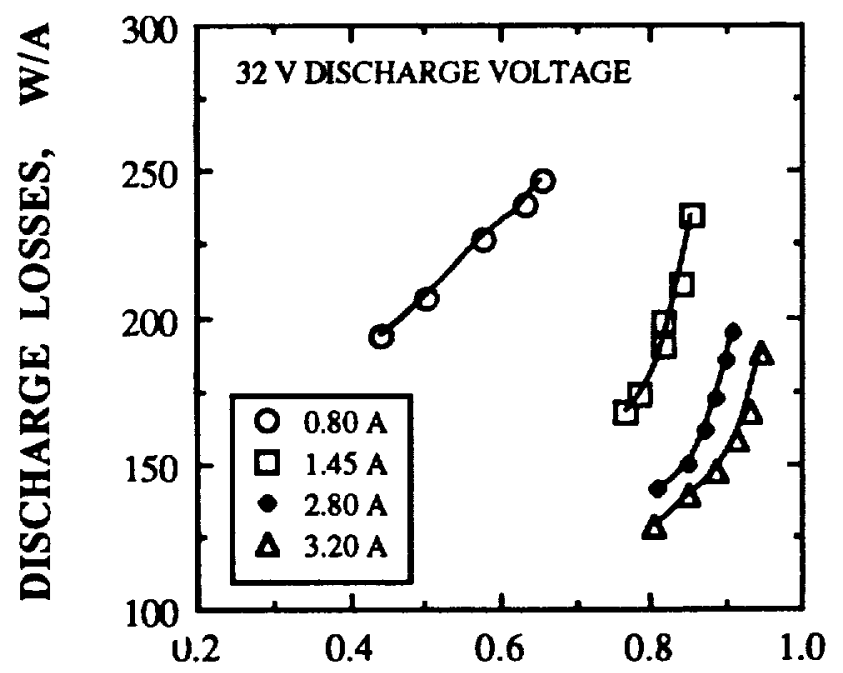

DISCHARGE CHAMBER PROPELLANT UTILIZATION EFFICIENCY

Fig. 2 Discharge losses versus discharge chamber propellant efficiency for several beam currents; grid set 2, krypton propellant.

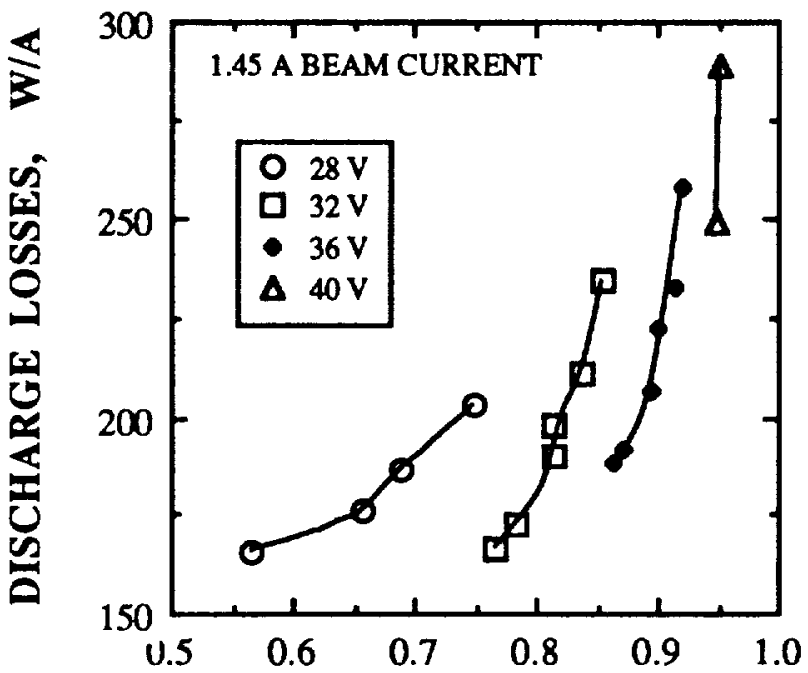

DISCHARGE CHAMBER PROPELLANT UTILIZATION EFFICIENCY

Fig. 3 Discharge losses versus discharge chamber propellant efficiency for several discharge voltages; grid set 2 , krypton propellant.

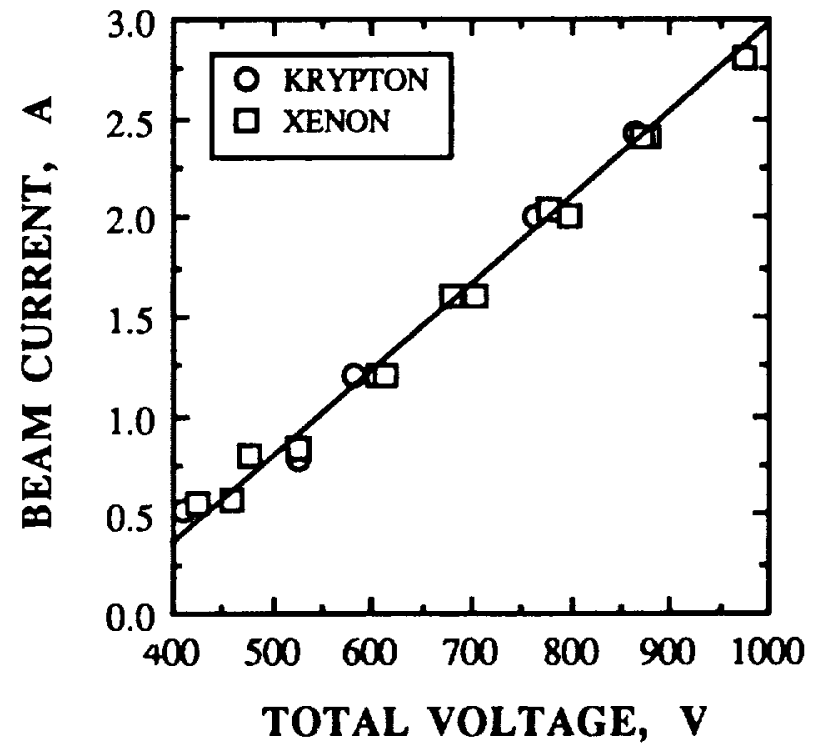

Fig. 4 Beam current versus total voltage for xenon and Lrypton propellants; grid set 1 . 


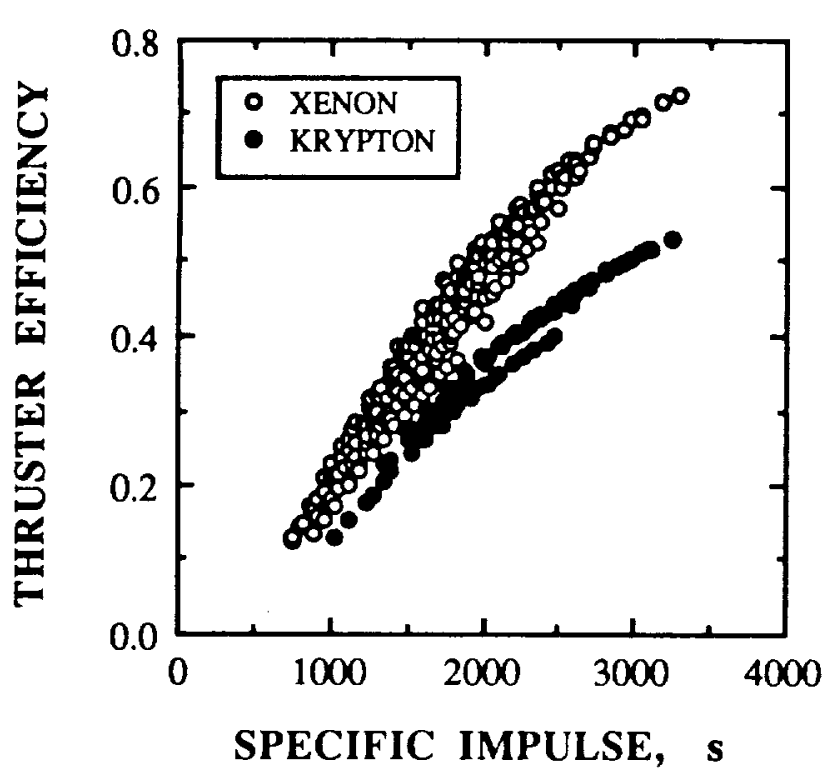

Fig. 5 Thruster efficiency versus specific impulse for xenon and krypton propellants; grid set 1 .

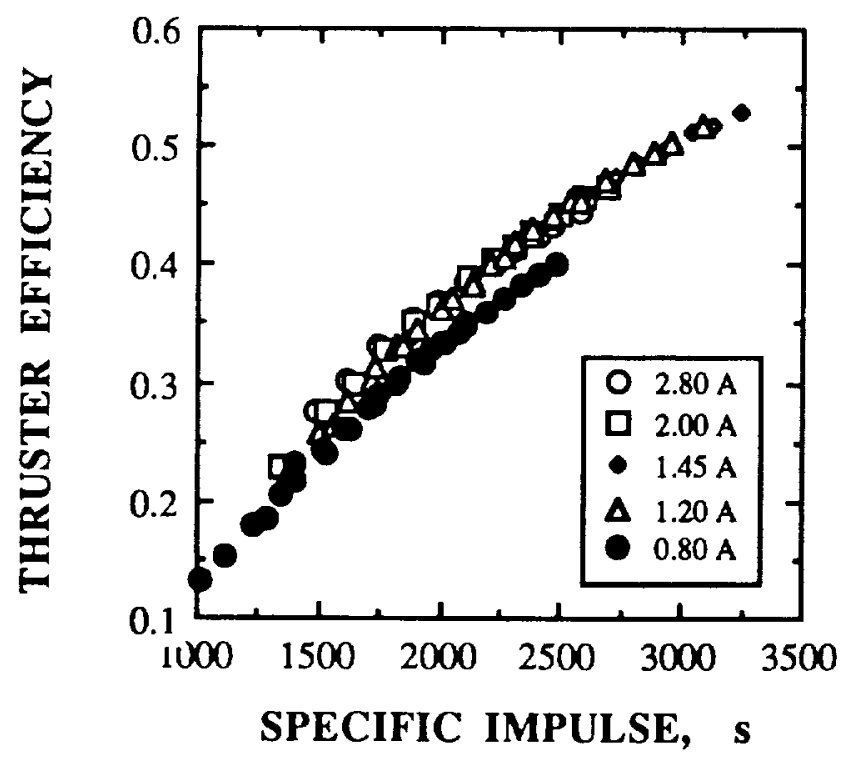

Fig. 6 Krypton thruster efficiency versus specific impulse for several beam currents; grid set 1 .

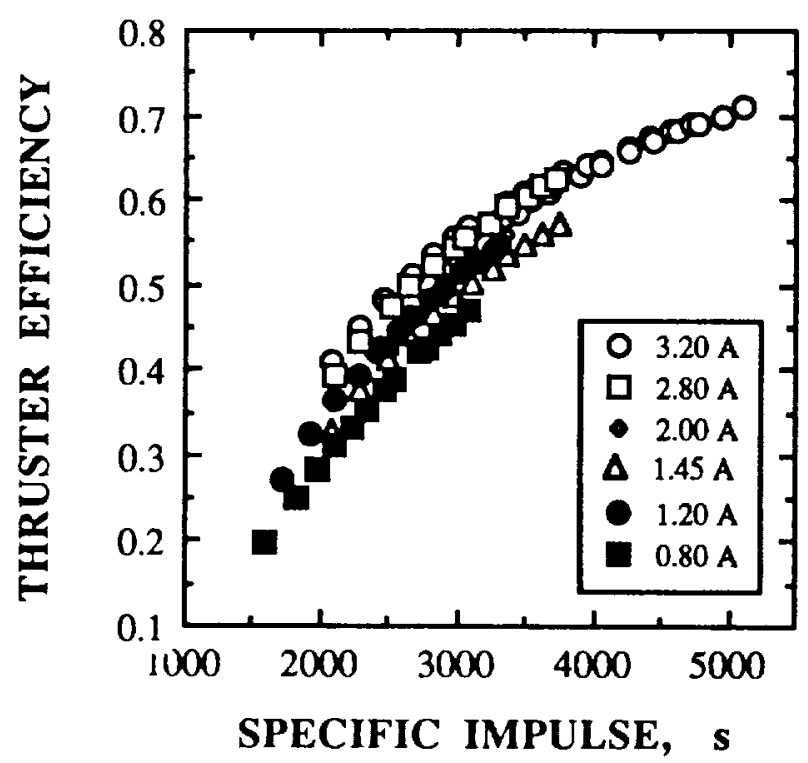

Fig. 7 Krypton thruster efriciency versus specific impulse for several beam currents; grid set 2.

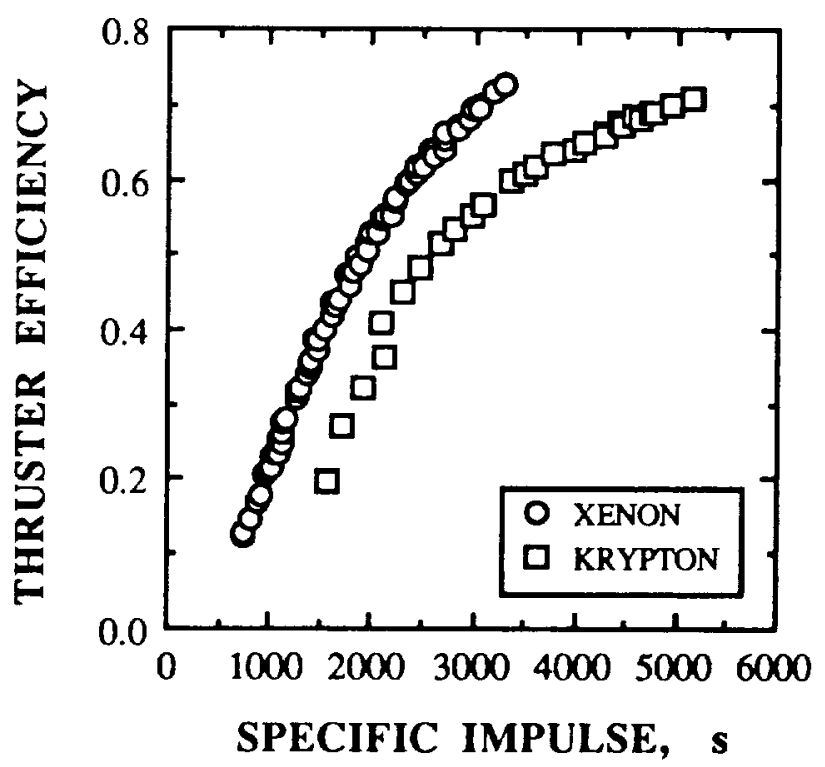

Fig. 8 Peak thruster effficiency versus specific impulse for xenon and krypton propellants. 


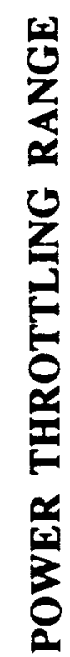

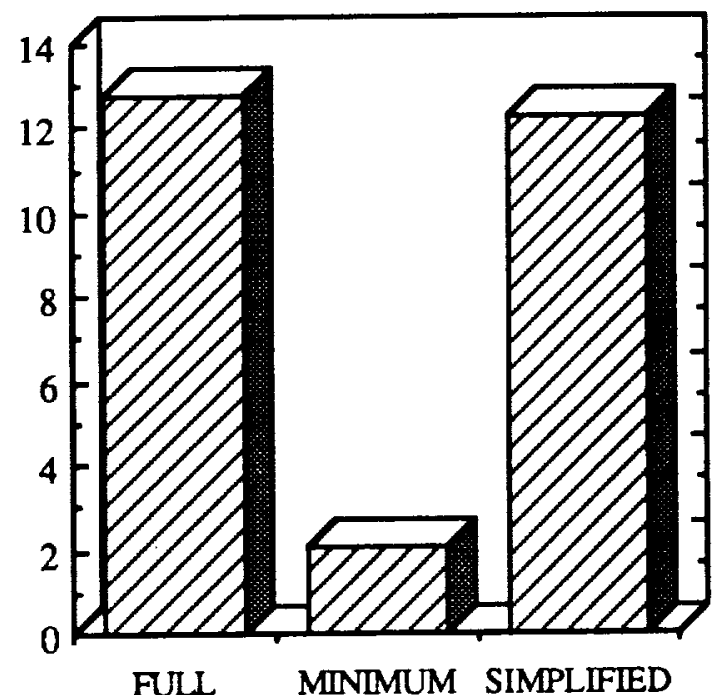

POWER THROTTLING STRATEGY

Fig. 9 Demonstrated power throttling range versus power throttling strategy with krypton propellant; grid set 2 .

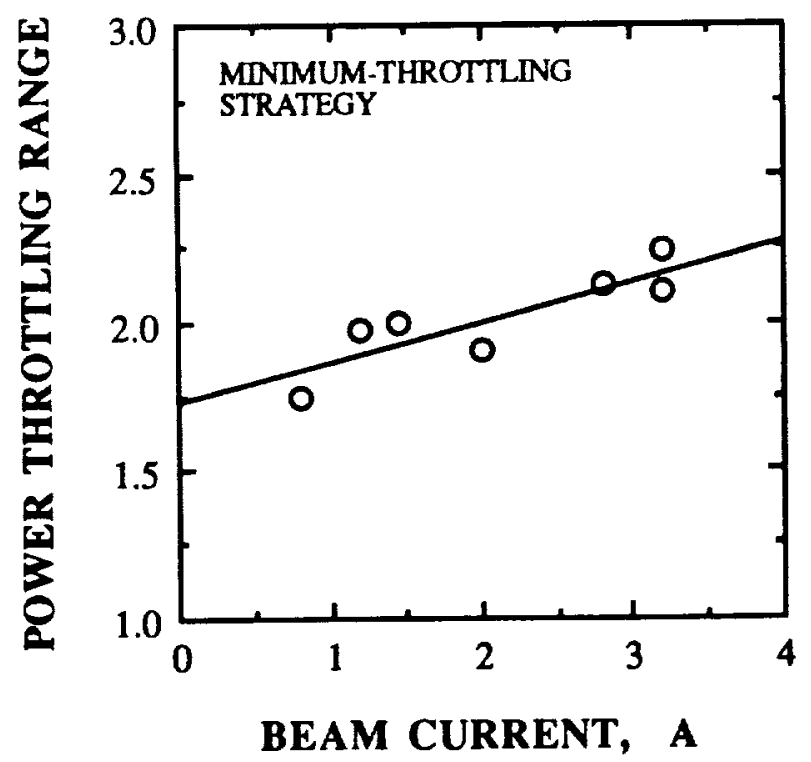

Fig. 10 Power throttling range versus beam current with krypton propellant for minimum power-throttling strategy; grid set 2 .

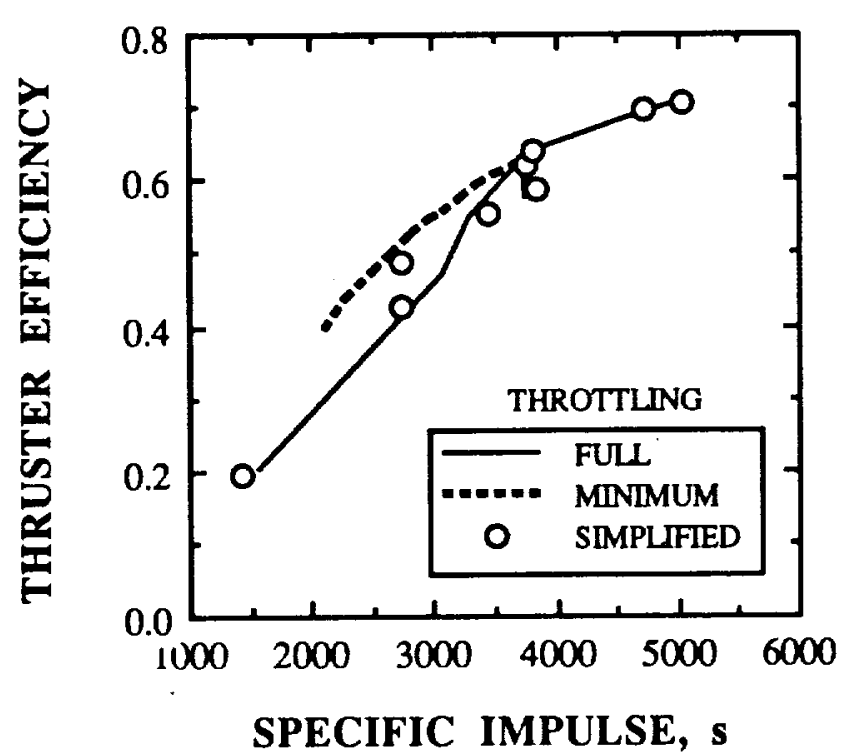

Fig. 11 Thruster efficiency versus specific impulse; comparison of power-throttling strategies with krypton propellant and grid set 2 .

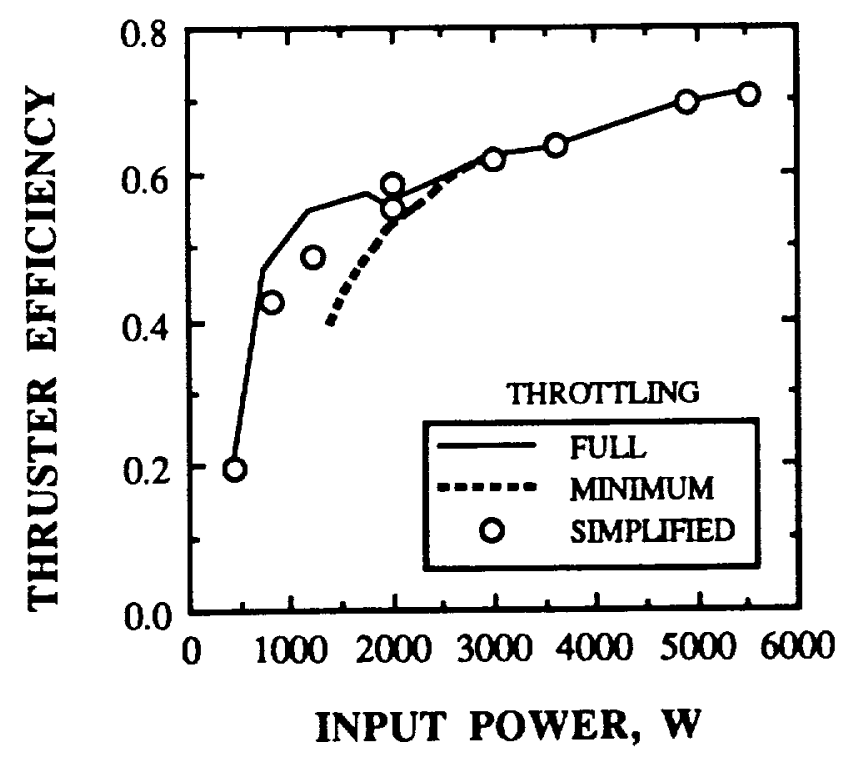

Fig. 12 Thruster efficiency versus input power; comparison of power-throttling strategies with krypton propellant and grid set 2 . 


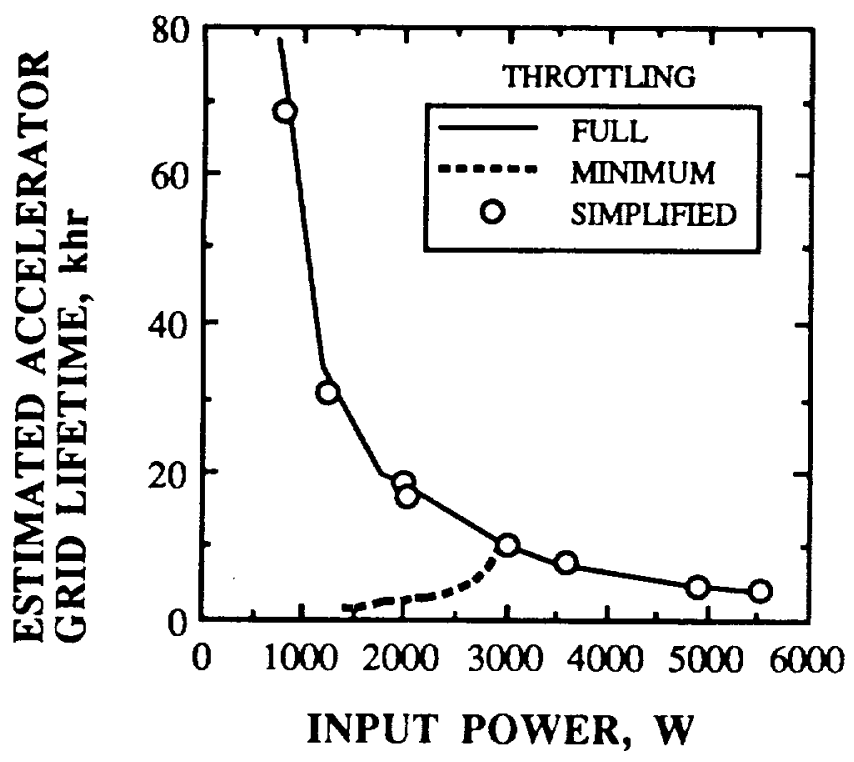

Fig. 13 Estimated accelerator grid lifetime versus input power; comparison of power-throttling strategies with krypton propellant and grid set 2 .

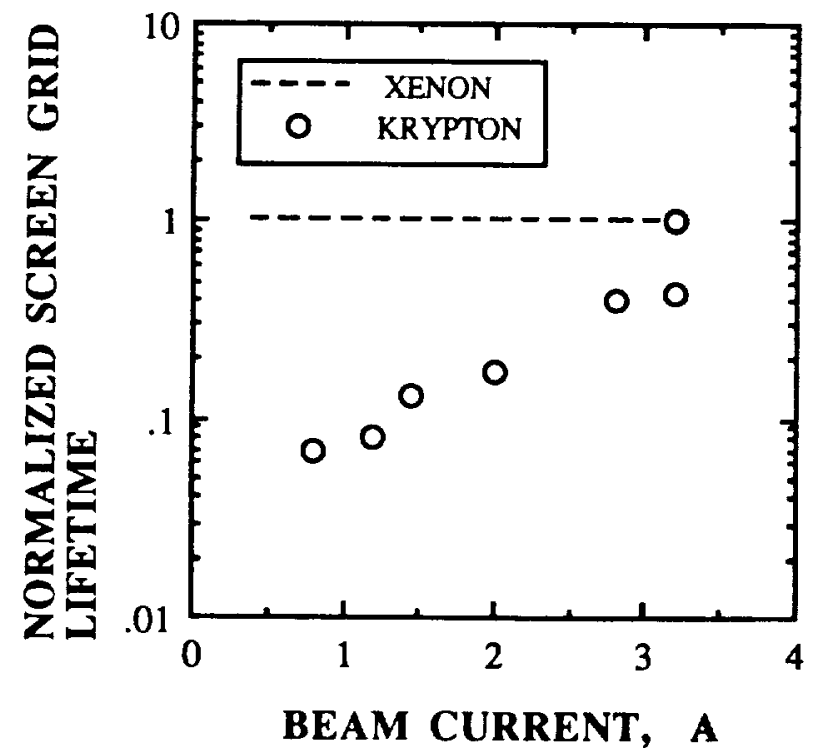

Fig. 14 Normalized screen grid lifetime versus beam current for xenon and krypton propellants. 


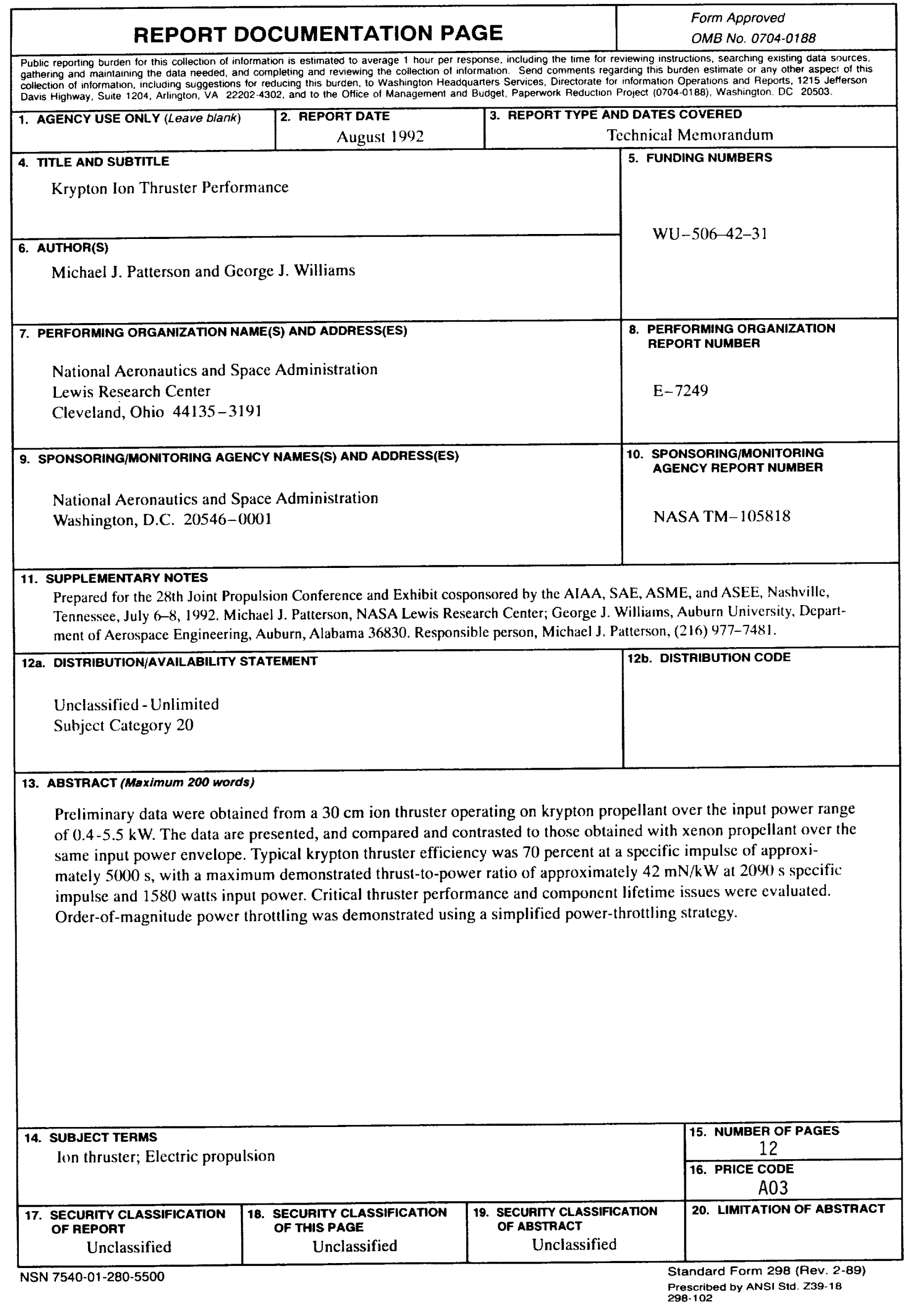

